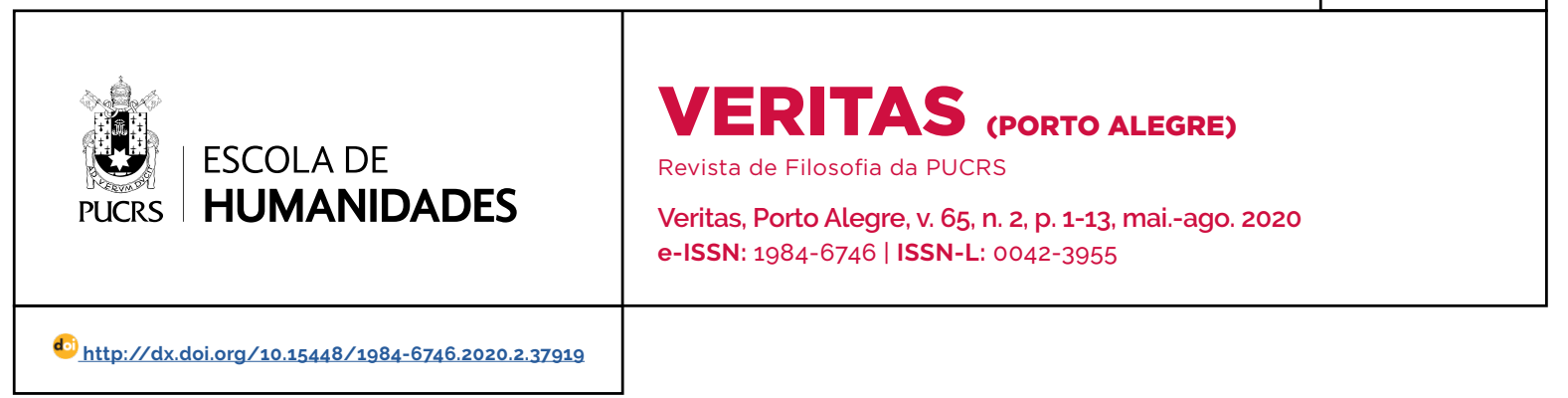

SEÇÃO: ESTÉTICA

\title{
Richer de Reims e suas Histórias: a construção narrativa - a estética como instrumento retórico (século $\mathrm{X}$ )
}

\author{
Richer de Reims and his Stories: narrative construction - aesthetics as a rhetorical \\ instrument (10th century) \\ Richer de Reims y sus historias: construcción narrativa - estética como instrumento \\ retórico (siglo $X$ )
}

\author{
Rafael Bassi ${ }^{1}$ \\ orcid.org/0000-0003-1289-2977 \\ bassi.r@hotmail.com
}

Recebido em: 30 abr. 2020. Aprovado em: 14 mai. 2020. Publicado em: 28 jul. 2020.
Resumo: O presente artigo objetiva discutir como Richer de Reims (941-998), monge beneditino do século $X$, compôs um relato histórico baseando na construção narrativa totalmente ligada ao aparato estético com instrumento retórico. A partir de sua formação clássica, organizada pelo Abade Gerberto de Aurillac (futuro papa Silvestre II), Richer constrói um texto de Histórias (Os Quatro Livros de História) que compõe uma narrativa a partir de uma fórmula estética particular, que é a "reescrita", ou "criação", dos diálogos dos diversos personagens que aparecem no relato; com isso, faz com que as supostas "vozes" de seus personagens ajudem-no na legitimação, política ou intelectual, daqueles para quem ele deixa transparecer sua preferência.

Palavras-chave: Richer de Reims. Estética narrativa medieval. Retórica medieval. Quatro livros de História.

\begin{abstract}
This article aims to discuss how Richer de Reims (941-998), benedictine monk of the 10th century, composed a historical account based on the narrative construction totally linked to the aesthetic apparatus as a rhetorical instrument. From his classic formation, organized by Abbot Gerbert of Aurillac (future Pope Silvestre II), Richer builds a text of Histories (The four books of History) that composes a narrative based on a particular aesthetic formula, which is "rewritten", or "creation" the dialogues of the various characters that appear in the story; with this, he makes the supposed "voices" of his characters help him in the legitimation, political or intellectual, of those for whom he shows his preference.

Keywords: Richer of Reims. Medieval aesthetics. Medieval rethoric. Four books of History.
\end{abstract}

Resumen: Este artículo tiene como objetivo discutir cómo Richer de Reims (941-998), monje benedictino del siglo X, compuso un relato histórico basado en la construcción narrativa totalmente mezclada al aparato estético usado cómo un instrumento retórico. Con sus estudios clásicos, organizado por el abad Gerberto de Aurillac (futuro Papa Silvestre II), Richer construye un texto sobre Historias (Los cuatro libros de Historia) que componen una narrativa basada en una fórmula estética particular, que es la "reescritura", o "creación", de los diálogos de los diversos personajes que aparecen en la historia; con esto, hace que las supuestas "voces" de sus personajes lo ayuden en la legitimación, política o intelectual, de aquellos por quienes muestra su preferencia.

Palabras clave: Richer de Reims. Estética medieval. Retórica medieval. Cuatro libros de Historia.

\section{(c) (1)}

Artigo está licenciado sob forma de uma licença Creative Commons Atribuição 4.0 Internacional. 


\section{Introdução}

O que se pretende com esse artigo é problematizar algumas concepções sobre a relação entre a construção retórica em um texto de história medieval, século $X$, e a estética enquanto composição, com o intuito de observar a sua construção justamente como instrumento retórico. Assim, busco demonstrar que o monge beneditino Richer de Reims ao escrever seu texto utilizou-se de composições frasais objetivando um uso retórico para defesa política de grupos dentro do contexto histórico do Reino dos Francos em que viveu. ${ }^{2}$

Richer de Reims, monge beneditino, entrou para a Abadia de Saint-Remi de Reims por volta de 969, permanecendo lá o resto de sua vida, ainda que não sejam claros os dados sobre a data exata e as condições de sua morte. Acredita-se que, por volta de 972, conheceu Gerberto de Aurillac, futuro papa Silvestre II, que, pessoalmente, o convidou, devido à necessidade de alguém para esta função, à escrita de uma obra de história. Outro dado que temos notícia é que a busca pelas informações que compuseram seu texto teve início por volta de 982. O que há entre esse periodo é lacunar, não se sabe ao certo, mas penso que uma interpretação coerente se dê na utilização desse periodo para a composição pessoal do seu aparato metodológico, da revisitação (ou primeira leitura) de textos clássicos sobre o assunto, ou seja, um periodo de aprendizado sobre qual seria sua função enquanto historiador, já que o título havia the sido dado por indicação e não por formação. ${ }^{3} \mathrm{~A}$ partir deste pedido são escritos Os Quatro Livros de História4 (991-998), que nós chamamos apenas de Histórias. Obra que, devido ao próprio pedido, é dedicada a Gerberto.

\section{A vida dos monges e os estudos a partir do texto de Richer}

No texto das Histórias, livro III, a partir do capitulo 38, vemos Richer expor as resoluções de um Sinodo, realizado, possivelmente, entre 976 e $983^{5}$ Nesta narrativa, podemos encontrar aspectos que soam necessários a discussões de nossos intuitos, como, por exemplo, o enaltecimento que ele faz da personagem escolhida como presidente do Sínodo, o abade Rodolfo, "homem de santa memória", 6 que pronuncia algumas palavras frente ao arcebispo João, enviado de Roma. A narração dos feitos dos grandes homens se faz presente, conforme era consenso entre os historiadores medievais e resultado da influência clássica na escrita da História, mas não apenas, pois me é extremamente interessante notar como ele elenca todo um discurso saído da própria fala do personagem. Richer inicia o capítulo 33 com as palavras proferidas por Rodolfo:

É grande coisa, padres santíssimos, que todos os bons se reúnam, se se comprometem a tentar obter o fruto da virtude. Na verdade, em tal modo se procura o benefício dos bons e o bom andamento das coisas, como, ao contrário, é danoso que se reúnam os malvados para tentar obter e fazer coisas ilicitas. Por isso, exorto-lhes, que creio estão reunidos em nome de Deus, a tentar obter coisas ótimas e lhes aviso a não fazer mover pelas nulidades das maldades. [...] Portanto, até hoje, muita coisa foi renunciada em sua santidade. Assim, julguei útil, estando vocês aqui reunidos pela graça de Deus, persuadi-los a querer e sentir a mesma coisa, a operar juntos a mesma coisa, por isso, graças a vontade comum, ao comum sentimento, à ação comum, que a virtude ne-

\footnotetext{
2 Esse pequeno ensaio é uma pequena parte das reflexões feitas na tese de doutoramento apresentada na Unicamp, em 2019 , intitulada: Sobre a História: uma análise da escrita, da produção autoral e da legitimação do poder nos Quatro Livros de História, de Richer de Reims. Disponivel em: http://repositorio.unicamp.br/jspui/handle/REPOSIP/335033. Acesso em: 21 abr. 2020.

3 Que só seria perceptivel com as universidades ou, então, com a contratação de pessoas para a função específica de relatar os eventos, como o fizeram alguns governos da Baixa Idade Média, principalmente no Ocidente medieval.

4 Utilizamos a seguinte nomenclatura para citação padrão para textos medievais: o nome do autor, sem sua designação de procedência, juntamente com a abreviação do nome de sua obra (no caso, HIST, como contração de Historiarum - em latim), seguindo do livro (que é como chamamos cada parte das obras dentro de um códice, e, por fim, o capítulo citado. Assim, comumente aparecerá: RICHER, HIST., Livro, capítulo. Quando o capítulo é citado a partir de seu título, colocamos também o seu nome em negrito.

5 Conforme Edição das Histórias, organizada por ROSSI, Paolo. Introduzione. In: SAINT-REMI, Richer di. I quatro libri delle Storie (888-998). Pisa: Edizioni Plus - Pisa University Press, 2008. p. 125, nota 832 da edição italiana.

$6 \quad$ RICHER, HIST, III, 32. Quod abbas Rodulfus abbatum primas fuerit

Interea tempos advenit. Abbates quoque ex diverso in unum collecti sunt. Quorum precipuus et primas constitutus est vir divae memoriae Rodulfus, ex coenobio sancti Remigii abbas. Quo presidente et prelaturae dignitatem tenente, alii circum dispositi sunt. Metropolitanus vero ex adverso in cliotedra resedit.
} 
gligenciada seja recuperada e a crença na maldade seja violentissimamente expulsa.?

O que me leva a compreender que as ordens sobre a forma de vida dos monges permaneciam muito fortemente enraizadas nas leis iniciais da Regra de São Bento, até mesmo fazendo um processo de retorno ao cumprimento da regra de maneira sentimental. O discurso, portanto, permanece conservador em relação às ações dos monges. $O$ texto richeriano aponta, em sua sequência, que houve concordância por parte dos monges com as palavras que estavam sendo ditas pelo abade.

Entretanto, podemos supor a importância do evento para a compreensão acerca dessa aceitação generalizada, afinal, o arcebispo estava presente e, na narrativa de Richer, parece assentir com o que está sendo falado pelo presidente dos abades. Permanece, no entanto, uma imagem de aceitação completa e unânime, haja vista as discussões que se seguem. O presidente dos abades começa a enumerar quais são os problemas por ele vistos e, contrariando a regra, exorta para que sejam proibidas algumas ações que têm sido cometidas ou que podem acontecer iminentemente. No capítulo 35, Rodolfo aponta para a impossibilidade, segundo a regra, de que alguém que tenha filhos possa querer fazer parte do monastério e da ordem. A esse problema, o arcebispo convoca a participação dos monges presentes, como aparece na fonte:

O venerável arcebispo, adicionando a isso [ao discurso proferido pelo abade Rodolfo] disse: "Se apetece ao sinodo, seja interdito". O sínodo disse: "Seja interdito". E assim pela autoridade do arcebispo e o consenso de todos, foi vetado. ${ }^{8}$

Seguem outras conclusões do abade Rodolfo, sobre, por exemplo, a necessidade de proibição da saída solitária de monges do monastério, ${ }^{9}$ ou a cor das vestimentas dos monges, que, segundo ele, devem manter-se com as vestes pretas, ${ }^{10}$ a superficialidade do uso de sapatos pelos monges, ${ }^{11}$ os demais tecidos e objetos supérfluos, tais quais os possiveis objetos de decoração, ${ }^{12}$ ou, então, as insinuações de dores corporais, consideradas pelo abade Rodolfo como "imorais".13 A todas essas

7 RICHER, HIST., III. 33. 'Magnum est, patres sanctissimi, bonos quosque convenire, si fructum virtutis quaerere elborent. Inde enim et bonorum utilitas et rerum honestas comparatur. Sicut econtra perniciosum, si pravi confluant ut illicita quaerant et expleant. Unde et vos, quos in dei nomine collectos arbitror, optima quaerere hortor atque ex malivolentia nihil moliri moneo. Amor secularis et odium apud vos locum nullum habeant, quibus enervatur iustitia, aequitas suffocatur. Vestri ordinis antiqua religio ab antiquitatis honestate, ut fama est, supra modum aberravit. Dissidetis enim inter vos in ipsa regularis ordinis consuetudine, cum aliter alter, alter aliter velit ac sentiat. Quapropter et sanctitati vestrae hactenus multum derogatum est. Unde et utile duxi ut vobis hic gratia dei in unum collectis suadeam idem vele, idem sentire, idem cooperar, ut eadem voluntate, eodem sensu, eadem cooperatione et virtus neglecta repetatur et pravitatis dedecus vehementissime propulsetur.'

8 RICHER, HIST., III, 35. Item indignatio primatis

'Quae enim vis impulit ut monachus intra claustra monasterii dominicis servitiis mancipandus compatrem habeat et compater dicatur? Et o, quantum nostro ordini dissentiat considerate. Si, inquam, compater est, ut a verisimili probabile efferam, cum eo qui pater est ipse est pater. Si vero pater est, filium vel filiam habere dubium non est. Unde et scortator potius quam monachus dicendus est. Sed quid de commatre? Quid in hoc nomine a secularibus perpenditur nisi turpitudinis consentanea? Hoc licet virisimile dicens, secularibus non preiudico, sed nostro ordini illicita repreendo. Quod quia ineptum videtur, vestra interminatione inhibendum est.' His venerandus metropolitanus subiungens, 'Si,' inquit, 'placet sinodo, interdicetur.' Sinodus dixit, 'Interdicatur.' Metropolitani itaque auctoritate, omnium consenso inhibitum est.

9 RICHER, HIST., III, 36. Alia primatis obiectio

Rursusque primas exorsus: 'Adhuc,' inquit, 'nostro ordini inimica proferam. In quo quidam dinoscuntur quibus mos inolevit ut soli a monasteriis egrediantur, soli foris nullo sui operis teste maneant, et quod pessimum est, absque fratrum benedictione et exeant et sine ea redeant. Unde non dubium est eos facilius posse falli quos fratrum orantium benedictio non munit. Inde est quod turpitudo vitae, morum pravitas, proprietatis peculium nobis a calumniantibus intenduntur. Unde etiam necesse est ut his calumniis subdamur, cum repulsioni testes habere non possimus. Hoc quoque vestra censura prohibeat.' Sinodus dixit, 'Prohibeatur.' Et memorabilis metropolitanus, 'Hoc quoque,' inquit, 'nostra auctoritate prohibemus. 10 RICHER, HIST., III, 38. De superfluo vestium colore

'Quid vero de colore vestium? Unde tantum deceptisunt, ut dignitatis merita coloribus comparent. Nam nisi tunica nigro colore deceat, ea indu' nullomodo placet. Quod si etiam nigro albus laneficii opere intermixtus sit, hic quoque talis vestem abiectam facit. Fulvus quoque abicitur. Nec minus niger nativus non sufficit, nisi etiam corticum inficiatur sucis. Atque haec de vestibus.'

11 RICHER, HIST., III, 39. De calciamentis superfluis

'De calciamentorum vero superfluitate quid referam? Tantum enim in his insaniunt, ut commoditatem sibi plurimam per ea auferant. Ea enim sic arta induunt, ut cippati pene impediantur. In quibus etiam rostra componunt, aures hinc inde erigunt. Et ne folleant, magnopere elaborant. Ut luceant quoque, famulis consciis indicunt.'

12 RICHER, HIST., III, 40. De linteis et operimentis superfluis

'Na lintea operosa atque pellicea operimenta sileam? Cum, inquam, a maioribus clementiae gratia pro lenis indui pellibus mediocribus concessum sit, vitium superfluitatis irrepsit. Unde et nunc peregrinis operimentis limbos bipalmos circumducunt atque pannis. Noricis ea desuper duplicant. Linteis vero pro stragulis minime uti concessum est, sed a quibusdam minus religiosis caeteris superfluis id additum est. Quorum numerus cum ex locis diversis plurimus esset, a pluralitate malorum bonorum paucitati id persuasum est.'

13 RICHER, HIST., III, 41. De femoralibus iniquis

'Sed quid femoralia iniqua referam? Horum etenim tibiales quater sesquipede patente atque ex staminis subtilitate etiam pudenda intuentibus non protegunt. In quorum compositione id uni non sufficit quo duo contenti ad plenum esse valerent. Haec coram hic relata na prohiberi velitis indicate. Caetera vero nostris conciliis in privato corrigenda sunt.' Sinodus dixit, 'Et prohibeantur.' 
questões, por parte do relato de Richer, aparece o consenso dos monges com as discussões colocadas pelo presidente Rodolfo. A impossibilidade dessa concordância generalizada se dá a partir da construção de um relato que seja muito mais plausivel do que real. Era mais uma espécie de autuação do presidente Rodolfo, aproveitando-se da presença do arcebispo, para reformular as ações dos monges que estavam presentes.

O arcebispo, ao que parece, fica, pelo texto de Richer, satisfeito com o resultado da reunião:

A estas coisas, o arcebispo acrescentou ainda: "De fato, foi próprio da vossa dignidade me salvaguardar dizendo poucas coisas; mas, porque o que condenamos é competência da vossa ordem, se julgarem que algumas coisas foram resolvidas de maneira correta por nós, em concilios reservados podem concordar e louvas as resoluções. Portanto, aquilo que a vossa sabedoria pediu, nossa autoridade proibiu. Sobre as coisas que a reservaram aos vossos silêncios, deixamos para que sejam mudadas de acordo com os vossos juizos". E, dito isto, o sinodo foi finalizado. ${ }^{14}$

Assim, a reunião foi concretizada, segundo o texto, com o consentimento de todos, e o sentimento, também geral, de que a regra tinha sido restabelecida e que as normas se mantinham intocáveis. As regras para a vida dos monges mantêm-se na mesma ortodoxia de sua fundação, com a aval coletivo. Mas o texto richeriano, nesse momento do enredo, sobre uma inversão grande, não dispensada de elogios pelo autor, quando, após essa reunião, passa ao relato da chegada de Gerberto a Reims. O que muda, certamente, são as inovações trazidas por Gerberto, que reformulara a forma de ensino dentro de Reims, no período de Richer.

\section{Os estudos de retórica de Richer de Reims}

Agora parto do pressuposto da construção da personagem Gerberto de Aurillac como exemplo de personagem digno de menção na História. Para tanto, acredito que o desenvolvimento do texto de Richer de Reims utiliza-se de uma elaboração retórica, onde ele constrói as imagens de ambos personagens, lhes dando as maiores virtudes e as melhores qualidades e características.

Reims constituía-se como um espaço com dinâmica educacional muito ampla, diversificada, e disponivel a seus monges, ${ }^{15}$ que passava pela lógica, pela retórica, astronomia, geometria, entre tantas outras. O que não se pode quantificar é o contingente de monges que se utilizou dessa disponibilidade. Richer de Reims, entretanto, foi um que aproveitou para aprofundar-se em temas bastante importantes, e, fundamentalmente, a retórica, como se pode perceber com o trecho a seguir:

[...] temendo que os seus alunos não pudessem adquirir a arte da oratória sem conhecer os modos de elocução que só se pode aprender nos poetas, utilizou, pois, estes últimos e achou por bem familiarizar os seus alunos com eles. Portanto, leu e comentou com eles os poetas Virgílio, Estácio e Terêncio, bem como os satíricos Juvenal, Pérsio e Horácio, e também o historiador Lucano. Assim que os seus alunos os conheceram bem e se instruiram na sua eloquência, introduziu-os na retórica. ${ }^{16}$

Aquém dos estudos sobre as obras dos comentadores contemporâneos a Richer, em Reims havia todo um esforço de possibilitar que os alunos se debruçassem nas leituras sobre as próprias obras que eram comentadas. Acredito que Richer, principalmente entre os anos de elaboração de sua metodologia para a escrita do seu texto, que acredito tenha sido os primeiros anos da década de 990 ,

\footnotetext{
14 RICHER, HIST., III, 42. Responsio metropolitani ad primatem

Ad haec quoque metropolitanus subiunxit: 'Gravitatis quidem vestrae fuit pauca dicendo pluribus parcere. Sed quoniam horum quae reprehensioni in vestro ordine subiacent, alia nobis, alia vero privatis conciliis corrigenda iudicatis, idem sentio, idem laudo. Unde et quae hic inhiberi vestra gravitas petit, nostra auctoritas interdicit. Quae vobis silendo reservastis, vestris relinquimus inmutanda iuditiis.' His quoque dictis, sinodus soluta est. Quo tempore monachorum religio admodum floruit, cum eorum religionis peritissimus metropolitanus huius rei hortator esset et suasor. Et ut nobilitati suae in omnibus responderet, aecclesiae suae filios studiis liberalibus instruere utiliter quaerebat.

15 Michel Sot analisa, de maneira bastante clara, a influência do espaço para a construção do método historiográfico em Flodoardo na obra Un historien et son Église au Xe s.: Flodoard de Reims. Paris: Fayard, 1993. Nesta obra, o autor explora todo o conjunto documental existente em Reims que se remetia às épocas merovingia e carolingia, e que, consequentemente, permanence durante o periodo de Richer de Reims. 16 RICHER, HIST. III, 47. Post quorum laborem, cum ad rhethoricam suos provehere vellet, id sibi suspectum erat, quod sine locutionum modis, qui in poetis discendi sunt, ad oratoriam artem ante perveniri non queat. Poetas igitur adhibuit quibus assuescendos arbitrabatur. Legit itaque ac docuit Maronem et Statium Terentiumque poetas, luvenalem quoque ac Persium Horatiumque satiricos, Lucanum etiam historiographum. Quibis assuefactos locutionumque modis compositos, ad rhethoricam transduxit.
} 
realizou essa atividade de maneira bastante incisiva. São essas leituras que o auxiliaram na elaboração prévia de como deveriam ser as Histórias que iria escrever, e cujo fundamento se dá nos exemplos de autores clássicos, em meu entender.

Todo esse conhecimento se dava, principalmente, a partir das modificações realizadas por Gerberto, e é por isso que sua chegada é descrita nas Histórias de maneira bastante efusiva pelo historiador. É, na visão de Richer, um ponto de inflexão sobre os estudos dentro do monastério. As transformações que foram feitas por Gerberto no local, referentes aos estudos dos monges, marca de forma bastante saliente a concepção de Richer e, além de tudo, cria no monge uma admiração intelectual que perdurará ao longo dos anos. Podemos dizer que Richer constrói na imagem de Gerberto como que uma figura de sabedoria e conhecimento a ser seguida. Talvez essa elegia a Gerberto tenha sido fundamental para um processo de aproximação entre os dois, o que, anos depois, fez com que Richer tenha sido o escolhido para a composição de um livro de história pelo próprio Gerberto. As relações pessoais se perderam para nossas pesquisas, mas ficou registrado nas Histórias todo o enaltecimento feito por Richer à figura proeminente do sábio Gerberto de Aurillac.

Não querendo abarcar discussões que são posteriores à historiografia contemporânea, poderia dizer que a construção imagética que faz Richer sobre Gerberto o coloca como um homem de saber ${ }^{17}$ medieval, ou até mesmo como um intelectual, ${ }^{18}$ ainda que esses termos sejam discutidos principalmente com o advento das cidades e, consequentemente, das universidades, na Baixa Idade Média. Portanto, o que quero dizer é que, para mim, Richer de Reims antecipa em mais de um século a construção da imagem daquilo que posteriormente será designado como um intelectual, um homem de saber. Entretanto, penso também que isto seja mais um ponto relacionado à construção retórica que ele faz sobre o personagem, mas que não deve ser visto de maneira dissociada da realidade, ou seja, ainda que tenha utilizado elementos que possam nos levar à compreensão sobre Gerberto enquanto um intelectual, não é possivel considerar esse como o único motivo, mas agrupá-lo ao interesse do historiador na construção narrativa sobre uma figura ideal. O que não o impediu de relacionar as mais variadas virtudes às características da sabedoria e da inteligência.

Foi enviado Gerberto, homem de grande inteligência e de eloquência admirável, graças a qual, em seguida, toda a Gália resplandeceu brilhantemente como uma lamparina ardente. Aquitano de nascimento, foi levado na infância ao convento do santo confessor Geraldo ${ }^{19}$, e ali aprendeu a gramática. Enquanto adolescente, ali residindo ainda, empenhado que era, apareceu Borrel, deque da Hispânia Citerior, veio ao convento para rezar. Sendo recebido com muita cordialidade pelo abade, demandou-lhe que, depois de vários discursos, que fossem enviados à Hispânia homens de muita instrução nas artes. Havendo este homem respondido prontamente de maneira afirmativa, o abade o persuadiu logo a escolher um dos religiosos do monastério e conduzi-lo consigo para apresentar-lhe as ciências. Longe de refutar, o duque consentiu generosamente ao pedido. Conduziu consigo Gerberto com o consenso dos confrades e o confiou ao bispo Attone para que o instruisse. Perto dele, Gerberto estudou de modo aprofundado e com sucesso a matemática. ${ }^{20}$

\footnotetext{
17 VERGER, Jacques. Homens de saber na ldade Média. Bauru, SP: EDUSC, 1999. Um completo apanhado sobre o estado das discussões acerca do conceito de "intelectual" durante o periodo medieval pode ser encontrado no artigo TEIXEIRA, I. S. O Intelectual na Idade Média: divergências historiográficas e proposta de análise. Revista Diálogos Mediterrânicos, Curitiba, v. 7. p. 155-173, 2014.

18 Jacques Le Goff assim se pronuncia sobre os saberes dos intelectuais, em clássico texto sobre o tema: "Entre tantas palavras: eruditos, doutos, clérigos, pensadores (a terminologia do mundo do pensamento sempre foi vaga), essa designa um meio de contornos bem definidos: o dos mestres das escolas. Anuncia-se na Alta Idade Média, desenvolve-se nas escolas urbanas do século XII, desabrocha a partir do século XIII nas universidades. Designa aquele cujo ofício é pensar e ensinar seu pensamento. Essa aliança da reflexão pessoal e de sua difusão num ensino caracteriza o intelectual." LE GOFF, J. Os Intelectuais na Idade Média. Rio de Janeiro: José Olympio, 2003. p. 23. Conforme saliento, a própria designação dada por Le Goff é resultado de um período posterior ao que trabalho, mas não posso me eximir de comparar essas investigações com as construções de Richer de Reims sobre a figura de Gerberto de Aurillac.

19 Abadia de Aurillac, segundo ROSSI, Paolo, 2008, Introduzione, nota 838, p. 128.

20 RICHER, HIST. III, 43. Adventus Gerberti Romam.

Cui etiam cum apud sese super hoc aliqua deliberaret, ab ipsa divinitate directus est Gerbertus, magni ingenii ac miri eloquii vir, quo postmodum tota Gallia acsi lucerne ardente vibrabunda refulsit. Qui Aquitanus genere, in coenobio sancti confessoris Geroldi a puero altus et grammatica edoctus est. In qua utpote adolescens cum adhuc intentus moraretur. Borrellum citerioris Hispaniae ducem orandi gratia ad idem coenobium contigitdevenisse. Qui a loci abate humanissime exceptus, post sermons quotlibet an in artibus perfecti in Hispaniis habeantur sciscitatur. Quod cum promptissime assereret, ei mox ab abate persuasum est ut suorum aliquem susciperet secumque in artibus docendum duceret. Dux itaque non abnuens, petenti liberaliter favit. Ac fratrum consensus Gerbertum assumptum duxit atque Hottoni episcopo instruendum commisit. Apud quem etiam in mathesi plurimum et efficaciter studuit.
} 
Com essa apresentação, Richer de Reims já dá a tônica de sua admiração e de como será a imagem sobre o personagem Gerberto de Aurillac. Por isso, o texto richeriano também deve ser compreendido como uma homenagem à figura não apenas exemplar no âmbito religioso e administrativo dentro da ordem, mas também intelectualmente. Acredito que o enaltecimento a esse personagem advenha da encomenda da escrita da obra histórica a Richer, mas penso que havia algo de verdadeiro na relação entre Richer e Gerberto: o reconhecimento de Richer sobre as virtudes de Gerberto, principalmente as relacionadas ao saber. Assim, ele aparece descrito com palavras de afeto e carinho, de enaltecimento e engrandecimento de suas ações frente às demais dos outros homens, incluindo os já considerados sábios anteriores à sua chegada.

Seu método de ensino em Reims foi bastante transformador para o que estavam acostumados, e se apresentava de maneira bastante didática, apontando para um conhecimento vasto e abrangente das disciplinas que lecionava, demonstrando diretrizes e contradições entre obras clássicas e seus mais diversos comentadores:

Ele explicou, portanto, com palavras claras a dialética percorrendo na ordem os seguintes livros: em primeiro lugar, Eisagoge, de Profirio, ou seja, a Introdução; segundo a tradução de Vittorino, o retórico, que explicou a mesma coisa, segundo Manlio; e, por fim, expôs o tratado de Aristóteles sobre as Categorias sem dificuldade. Mostrou, depois, perfeitamente, quais empenhos requer o tratado Peri Hermeneias, que é "Da intepretação", ensinou, depois, aos seus ouvintes também os Tópicos, que é o fundamento das provas, traduzido por Tullio do grego ao latim e explicado pelo cônsul Manlio com seis livros de comentários. ${ }^{21}$

Assim, o currículo existente em Reims aparentava preparar os monges para diversas disciplinas, e, quando da chegada de Gerberto, também foi passivel de uma alteração bastante brusca, mas que não sofreu grande resistência por parte dos alunos. Muito pelo contrário, houve grande alegria pelo recebimento das novas lições, pelo menos para Richer de Reims.

O que mais se destacava nas alterações era a maciça presença de autores gregos, que foram traduzidos pela tradição eclesiástica e que eram amplamente usados durante esse periodo para a formação monacal. E na própria apresentação de Gerberto aos estudantes de Reims, já se nota nas Histórias duas características fundamentais para a análise que proponho: a sua capacitação para o ensino de textos clássicos, com uma demonstração de conhecimento bastante salutar, além de um aparato baseado em autores que buscam na construção narrativa aliar a lógica com a retórica e a oratória. Isso fica mais claro na passagem que se segue no texto richeriano:

\begin{abstract}
Leu também e comentou de modo conveniente os quatro livros sobre os diferentes tópicos, os dois livros sobre os silogismos categóricos, os três livros sobre os silogismos hipotéticos, o livro único sobre as definições e o livro igualmente único sobre as divisões ${ }^{22}$. Depois do estudo destas obras, querendo que os seus alunos avançassem no estudo da ciência retórica, temia que não fosse possivel elevar-se à arte da oratória sem aquele modo de eloquência que deve ser inspirado nos poetas. Portanto, usou como recurso a citação dos poetas aos quais julgava úteis se familiarizar. E assim leu e comentou os poetas Marone. Stazio e Terêncio, como também os satíricos Juvenal, Pérsio e Orácio, e também o histórico Lucano. Depois que foram familiarizados com estes autores e instruidos sobre os seus modos de elocução, fez passar à retórica. ${ }^{23}$
\end{abstract}

A leitura de Gerberto sobre as obras faz com que os alunos compreendam a necessidade de outras disciplinas, e é por isso que, notando a demanda por mais autores, ele começa o processo de modificação do currículo dos estudos em Reims. Justin Lake defende que a ação de

\section{$21 \quad$ RICHER, Hist. III, 46. Quem ordinem librorum in docendo servaverit}

Dialecticam ergo ordine librorum percurrens, dilucidis sententiarum verbis enodavit. Inprimis enim Porphirii ysagogas, id est introductiones, secundum Victorini rhethoris translationem, inde etiam easdem secundum Manlium explanavit, Cathegoriarum, id est predicamentorum, librum Aristotelis consequenter enucleans. Periermenias vero, id est de interpretatione librum, cuius laboris sit aptissime monstravit. Inde etiam topica, id est argumentorum sedes, a Tullio de Greco in Latinum translata et a Manlio consule sex commentariorum libris dilucidata, suis auditoribus intimavit.

22 Todas as obras citadas são de Boécio.

23 RICHER, Hist., III, 47. Quid provehendis rhethoricis providerit

Necnon et quatuor de topicis differentiis libros, de sillogismis cathegoricis duos, de ypotheticis tres, diffinitionumque librum unum, divisionum aeque unum utiliter legit et expressit. Post quórum laborem, cum ad rhethoricam suos provehere vellet, id sibi suspectum erat, quod sine locutionum modis, qui in poetis discendi sunt, ad oratoriam artem ante perveniri nom queat. Poetas igitur adhibuit quibus assuescendos arbitrabatur. Legit itaque ac docuit Maronem et Statium Terentiumque poetas, luvenalen quoque ac Persium Horatiumque satiricos, Lucanum etiam historiographum. Quibus assuefactos locutionumque modis compósitos, ad rhethoricam transduxit. 
Gerberto dentro de Reims foi a de "reviver os estudos de retórica clássica", ${ }^{24}$ renovando-os a partir de comentadores contemporâneos, que transitavam em um período de retomada das obras de Cícero, principalmente. ${ }^{25}$

As transformações realizadas por Gerberto não se mantiveram restritas aos estudos retóricos, pois ele também difundiu os estudos sobre a matemática, de onde surgiu a construção de um abaco, ${ }^{26}$ ensinando aos monges até mesmo como se fazer uma esfera sólida ${ }^{27}$ para explicá-la geometricamente. Estudos de grego e latim também se mostraram presentes, ${ }^{28}$ pois eram necessários para as compreensões etimológicas. Também realizou a construção de outra esfera para a análise dos planetas, ${ }^{29}$ e, a partir dela, desenvolver conhecimentos acerca das estrelas. ${ }^{30}$ Mas foi, certamente, no âmbito da filosofia que Gerberto mais desenvolveu estudos com os alunos, criando uma divisão da disciplina que está disposta da seguinte maneira, narrada a partir de um embate entre Gerberto e Otric, no qual, após ser questionado sobre seu não entendimento acerca da suposta divisão que ele afirma existir em filosofia:

Gerberto responde agora: "Porque isso tem uma grande importância, enquanto compreensão da verdade sobre as coisas divinas e humanas, para não ser acusado de preguiça e pelos beneficios de alguns dos nossos ouvintes, não hesitarei em expor essa divisão segundo Vitorino e Boécio. A filosofia é um gênero cujas espécies são a prática e a teoria; a prática, de sua própria parte, tem as suas espécies, que são a dispensativa [economia], a distributiva [ética] e a civil [política]. Na teoria é em vez disso incluida a fisica natural, a matemática inteligivel e a teologia. Nós, contudo, não colocamos sem razão a matemática abaixo da física. ${ }^{31}$

24 LAKE, Justin. Gerbert of Aurillac and the Study of Rhetoric in Tenth-Century Rheims. The Journal of Medieval Latin, Toronto, v. 23, p. 49-85, 2013a. p. 50.

25 Ibidem, p. 51.

26 RICHER, HIST., III, 54. Confectio abaci

In geometria vero non minor in docendo labor expensus est. Cuius introductioni abacum, id est tabulam dimensionibus aptam, opere scutaril effecit.Cuius longitudini in XXVII partibus diductae, novem numero notas omnem numerum significantes disposuit. Ad quarum etiam similitudinem mille corneos effecit caracteres, qui per XXVII abaci partes mutuati, cuiusque numeri multiplicationem sive divisionem designarent tanto compendio numerorum multitudinem dividentes vel mutiplicantes, ut pre nimia numerositate potius intelligi quam verbis valerent ostendi. Quorum scientiam qui ad Constantinum grammaticum. Ibi enim haec satis habundanterque tractata inveniet.

27 RICHER, HIST., III, 50. Sperae solidae compositio

Ratio vero astronomiae quanto sudore collecta sit dicere inutile non est, ut et tanti viri sagacitas advertatur et artis efficacia lector commodissime capiatur. Quae cum pene intelectibilis sit, tamen non sine admiratione quibusdam instrumentis ad cognitionem adduxit. Inprimis enim mundi speram ex solido ac rotundo ligno argumentatus, minoris similitudine maiorem expressit. Quam cum duobus polis obliquaret, signa septentrionalia polo erectiori dedit, australia vero deiectiori adhibuit. Cuius positionem eo circulo rexit qui a Grecis orizon, a Latinis limitans sive determinans appellatur, eo quod in eo signa quae videntur ab his quae non videntur distinguat ac limitet. Qua in orizonte sic collocata, ut et ortum et occasum signorum utiliter ac probabiliter demonstraret, rerum naturas dispositis insinuavit instituitque in signorum comprehensione. Nam tempore nocturno ardentibus stellis operam dabat, agebatque ut eas in mundi regionibus diversis obliquatas tam in ortu quam in occasu notarent.

\section{RICHER, HIST., III, 51. Intellectibilium circulorum comprehensio}

Circuli quoque qui a Grecis paralleli, aLatinis aequistantes dicuntur, quos etiam incorporales esse dubium non est, hac ab eo arte comprehensi noscuntur. Effecit semicirculum recta diametro divisum. Sed hanc diametrum fistulam constituit, in cuius cacuminibus duos polos boreum et austronothum notandos esse instituit. Semicirculum vero a polo ad polum XXX partibus divisit. Quarum sex a polo distinctis, fistulam adhibuit per quam circularis linea arctici signaretur. Post quas etiam V diductis, fistulam quoque adiecit quae aestivalem circulationem indicaret. Abinde quoque quatur divisis, fistulam identidem addidit unde aequinoctialis rotunditas commendaretur. Reliquum vero spatium usque ad notium polum eisdem dimensionibus distinxit. Cuius instrumenti ratio in tantum valuit, ut ad polum sua diametro directa, ac semicirculi productione superius versa, circulos visibus inexpertos scientiae daret atque alta mamoria reconderet.

29 RICHER, HIST., III, 52. Sperae compositio planetis cognoscendis aptissima

Errantiumque quoque siderum circuli cum intra mundum ferantur et contra contendant, quo tamen artificio viderentur scrutanti non defuit. Inprimis enim speram circularem effecit, hoc est ex solis circulis constantem. In qua circulos duos qui a Grecis coluri, a Latinis incidentes dicuntur, eo quod in sese incidant, complicavit; in quorum extremitatibus polos fixit. Alios vero quinque circulos, qui paralleli dicuntur, coloris transposuit, ita ut a polo ad polum XXX partes sperae medietatem dividerent, idque non vulgo neque confuse. Nam de XXX dimidiae sperae partibus a polo ad primum circulum sex constituit; a primo ad secundum, quinque; a secundo ad tertium, quatuor: a tertio ad quartum, itidem quatuor; a quarto ad quintum, quinque; a quinto usque ad polum, sex. Per hos quoque circulos eum circulum obliquavit qui a Grecis loxos vel zoe, a Latinis obliquus vel vitalis dicitur, eo quod animalium figuras in stellis contineat. Intra hunc obliquuum errantium circulos miro artificio suspendit, quorum absidas et altitudines, a sese etiam distantias, efficacissime suis demonstravit. Quod quemadmodum fuerit, ob prolixitatem hic ponere commodum non est, ne nimis a proposito discedere videamur.

3o RICHER, HIST., III, 53. Aliae sperae compositio signis cognoscendis idônea

Fecit preter haec speram alteram circularem, intra quam circulos quidem non collocavit, sed desuper ferreis atque aereis filis signorum figuras complicavit. Axisque loco fistulam traiecit per quam polus caelestis notaretur, ut eo perspecto, machina caelo aptaretur. Unde et factum est ut singulorum signorum stellae singulis huius sperae signis clauderentur. Illud quoque in hac divinum fuit, quod cum aliquis artem ignoraret, si unum ei signum demonstratum foret, absque magistro cetera per speram cognosceret. In qua etiam suos liberaliter instruxit. Atque haec actenus de astronomia.

${ }_{31}$ RICHER, HIST., III, 60. Reprehensio divisionis ab Otrico inutilis, ac Gerbert responsio

Ad haec Otricus, innuente augusto, sic ait: 'Quoniam philosophiae partes aliquot breviter attigisti, ad plenum aoportet ut et divisionem enodes. Sicque fieri poterit ut ex probabili divisione vitiosae figurae suspicion a te removeatur'. Tunc quoque Gerbertus, 'Cum hoc', inquit, 'magni constet, utpote divinarum et humanarum rerum comprehension veritatis, tame nut nec nos ignaviae arguamur, et auditorium aliqui proficere possint, secundum Vitruvii atque Boetii divisionem dicere non pigebit. Est enim philosophia genus cuius species sunt practice et theoretice. Practices vero species dico dispensativam, distributivam, civilem. Sub theoretice vero non incongrue intelliguntur phisica naturalis, mathematica intelligibilis, ac theologia intelectibilis. Rursusque mathematicam sub phisica non preter rationem collocamus'. 
Teorizar as concepções filosóficas nas Histórias de Richer de Reims demonstra, mais uma vez, um excerto com objetivo duplo: tanto narrar a figura de Gerberto como conhecedor das disciplinas que evoca, quanto o próprio aluno Richer de Reims aparecer como alguém que apreendeu os conteúdos e soube mantê-los a ponto de poder, anos depois, frente à escrita, retomá-los em episódios anteriores.

Vejo o trabalho desta pesquisa como a busca por compreender esse espaço como um local onde os preceitos culturais estão relacionados tanto com a formação clássica quanto com a formação cristã, que predomina nos estudos e nas formulações das mais variadas disciplinas. Esse aparato será fundamental para o desenvolvimento de concepções sobre a escrita da história. E, consequentemente, faz com que se compreenda como os estudos de Richer foram fundamentais para a atual análise sobre o texto das Histórias.

Entretanto, saliento que a obra histórica de Richer deve, a partir de agora, ser compreendida como o resultado de uma metodologia criada a partir dos estudos disponiveis nesse ambiente cultural que era Reims. O resultado é um trabalho consciente que, ao selecionar os eventos, acaba por dar a eles um direcionamento, principalmente com uma ordenação em estilo retórico e temporal, ou seja, Richer de Reims constrói uma narrativa histórica onde, a partir da escolha de alguns personagens, cria um dado de enaltecimento de Gerberto, deixando para seu público leitor a ideia de que aquele personagem é um sujeito ideal, e a de que as suas ações deverão ser ouvidas e realizadas para a busca escatológica do que é o melhor para quaisquer eventos.

Se pensarmos que o modelo de Cluny, segundo Constance Bouchard e Dominique logna-Prat propõem, é um dos fundamentos que demonstra o domínio da Igreja e o domínio da realeza sobre os demais ${ }^{32}$, podemos salientar que as questões, os contextos políticos, estão intimamente relacionados com a escrita, com a produção dessa escrita. E o mesmo se torna observável em Reims, como pressupõe Jason Green, ao expor sua tese sobre a obra de Richer de Reims:

Com esse estudo eu gostaria de sugerir que o
ato de escrita de nossos autores constitui um
tipo de escrita, ela mesma, relacionada com a
comunidade politica. [...] Nós podemos então
explorar com grande riqueza o que a politica
significa para esse pessoal que observa, que ex-
perimenta, rememora e, nas formas disponiveis
participa e se engaja na política do seu mundo. ${ }^{33}$

Portanto, o ato da escrita da história era compreendido nesses espaços não apenas como um ato de rememoração do passado, mas sim como um processo de narrativa ordenadora dos eventos. A partir do pressuposto que estes autores selecionam, novamente, de maneira ordenada os eventos, conseguimos discutir aspectos autorais que são relacionáveis à sua consciência no momento da construção da escrita, demonstrando, assim, seus próprios objetivos. O que fazem, portanto, não é um mero ajuntamento de eventos que são postos em um sentido cronológica, mas sim a escrita que se utiliza de diversos recursos, métodos, esquemas, para a compreensão dos eventos e a sua relação com o tempo presente.

\section{A construção dos diálogos: um aspecto estético que compõe a retórica}

Desde o início das análises sobre o texto richeriano, debrucei-me em uma particularidade evidente que me chamou tamanha atenção: a composição das falas. Ao longo de todo o texto, aparecem entremeadas no relato do autor as falas dos personagens. Isso pode ser verificado nas citações acima, em que aparecem discursos complexos dos personagens, entretanto, elegi a que se segue para a discussão que proponho: Neste periodo Reginaro, homem de alta paten-
te e nobre, referenciado como aquele que tem
Pescoço Longo, cuja morte deixou em grande
situação de ruina a Bélgica, reuniu-se ao fim
da vida no palácio de Meerssen, ${ }^{34}$ ferido e
oprimido por uma doença geral sobre o corpo.

\footnotetext{
BOUCHARD, Constance B. Feudalism', Cluny, and the Investiture Controversy. In: BLANKS, David; FRASSETTO, Michael; LIVINGSTONE, Amy. Medieval monks and their world: ideas and realities. Leiden/Boston: Brill, 2006. p. 85.

33 GLENN, Jason. Politics and History in the Tenth Century. The work and world of Richer of Reims. Cambridge: Cambridge University Press, 2004. p. 14-15.

34 Perto de Maastricht, atualmente.
} 
Conta-se que o rei Carlos participava do seu séquito, e com os olhos cheios de lágrimas disse: "De alto e baixo! Do amplo ao restrito!, referindo-se do ato à pessoa, do outro ao monumento. Completou o funeral, concordando com grande generosidade com Gisleberto, filho de Reginaro, já tornando-se um jovem homem, a carga paterna, à presença dos príncipes que eram espectadores. ${ }^{35}$

O evento descrito é de cerca do ano de 915 . antecede até mesmo o início do texto de Flodoardo, mas, mesmo assim, aparece descrito na obra de Richer de Reims. A construção - ou reconstrução - da cena apresenta algumas regras estilisticas bastante recorrentes em Richer de Reims, como a descrição do estado de Carlos, frente ao cortejo fúnebre: olhos cheios de água / "ac oculos lacrimis suffusus". Esse é um exemplo claro da construção feita por Richer de Reims e, não podemos nos esquecer que não foi, em hipótese alguma, omitida pelo autor, pois, já no Prólogo, ele anuncia a sua busca de informações em Flodoardo, por exemplo. Entretanto, o que aparece como inusitado é a descrição física que é retomada ao longo de todo o texto, além da criação das palavras proferidas por Carlos.

Por isso, me parece fundamental nos questionarmos sobre os motivos que levaram Richer de Reims a fazer tal construção, já que me parece impossivel saber se ele de fato conseguiu essa "declaração" a partir de alguma documentação específica. Penso que uma explicação primeira resida no ideal narrativo, no estilo de texto richeriano, que acompanha o autor aonde quer que ele vá. ${ }^{36}$ Entretanto, esse evento é bastante anterior ao cerne da obra de Richer, o que me leva a elucubrar que, ainda que perceptivel desde o inicio do seu texto, o estilo que é presente ao longo de toda a obra leva a uma construção retórica que, desde os primeiros capítulos do Livro I, mas principalmente a partir do Livro III, demonstra o objetivo que o autor possuia de defender algumas personagens em detrimento de outras. Em outras palavras, esse recurso linguístico do estilo será utilizado para a defesa de alguns sujeitos especificos. Torna-se primordial averiguar, desta feita, como Richer de Reims construiu seu aparato retórico e o que essa influência - que, já adianto, vem de Cícero - pode auxiliá-lo em seus objetivos políticos.

Os diálogos são ficcionais, e as conversações e composições dramáticas foram herdadas de uma antiguidade que remontava a Tito Livio, Salústio e Hegésipo, para citar alguns exemplos de influências que Richer de Reims teve, ${ }^{37}$ mas havia também a necessidade da narrativa estar ancorada na plausibilidade que despertaria no leitor não apenas a surpresa, mas, também, a crença naquilo que estava sendo escrito. Como bem coloca Verônica da Costa Silveira em sua tese:

A definição de "história" nas Etimologias ${ }^{38}$ de Isidoro de Sevilha é ilustrativa da concepção mais fundamental sobre o significado do termo. História jamais é empregada na obra do Hispalense, e tampouco fora na de Jordanes, para se referir ao tempo passado propriamente dito. História era um gênero narrativo cujo objeto eram os eventos passados, sua raiz etimológica vem do grego que significa ver e conhecer, pois a peculiaridade da narrativa histórica era narrar sem falsidade o que era digno de recordação. ${ }^{39}$

\footnotetext{
35 RICHER, HIST. I, 34: Hac etiam tempestate Ragenerus, vir clarus et nobilis, cognomento Collo longus, cuius etiam obitus multam rei publicae in Belgica intulit labem, communi corporis valitudine tactus et oppressus, finem vitae apud Marsnam palatium accepit. Cuius exequiis Karolus rex interfuisse dicitur, ac oculos lacrimis suffusus dixisse, 'O'. Inquiens, 'ex alto humilhem, ex amplo artissimum', altero personam, altero monumentum significans. Peractisque exsequiis, Gisleberto eius filio, iam facto iuveni, paternum honorem coram principibus qui confluxerant liberalissime accommodat.

${ }_{36}$ Novamente recorro aos estudos de Carlo Ginzburg, quando apresenta a busca pela falsificação das obras a partir dos detalhes, como o lóbulo da orelha de uma obra verdadeira e o de uma obra falsa. Esses pequenos detalhes, que são intrínsecos a um autor, mesmo que sem sua própria percepção, são os vestígios de que devem ser buscados pelos pesquisadores. A isso eu chamei de estilo richeriano. GINZBURG. Carlo. Sinais. Raizes de um paradigma indiciário. In: GINZBURG, Carlo. Mitos, Emblemas, Sinais. São Paulo: Companhia das Letras, 1989. p. 144. 37 LAKE, Justin. Richer of Saint-Rémi. The Methods and Mentality of a Tenth-Century Historian. Washington: Catholic University of America Press, 2013. p. 186.

${ }_{38}$ A análise de Verônica da Costa Silveira parte da análise do trecho da obra Etimologias, I, 41, onde Isidoro de Sevilha explicita que: "História é a narração de acontecimentos, pela qual se conhecem os sucessos que tiveram lugar em tempos passados. O nome de história deriva do grego historien, que significa ver ou conhecer. E é que entre os antigos não escrevia história quem não tenha sido testemunha e havia visto os feitos que deveriam narrar. Melhor conhecermos os feitos que observamos com nossos próprios olhos que os que conhecemos por ouvido. 2. As coisas que se vê podem ser narradas sem falsidade. Esta disciplina se integra à gramática porque às letras se confia quando é digno de recordação".

39 SILVEIRA, Verônica da Costa. Identidades Políticas e Políticas Identitárias na Gália Merovíngia e Hispânia Visigoda. 2015. Tese (Doutorado em História). Programa de Pós Graduação em História Social, Faculdade de Filosofia, Letras e Ciências Humanas, Universidade de São Paulo, São Paulo, 2015. p. 252.
} 
Pois se o que busca é a narração dos eventos sem falsidade acerca do que era digno de recordação, a seleção de quais eventos seriam dignos de narração frente à ampla quantidade deles disponivel, era responsabilidade do autor medieval. Ao escolher, acredito que Richer de Reims usava essa autonomia para sua própria construção retórica. Esta utilização remonta a Cícero, com sua Rethorica ad Herennium, ${ }^{40}$ por exemplo:

Apresentar seu caráter pelo discurso, então, como justo, integro, religioso, timorato, tolerador de injustiça, tem um poder absolutamente admirável; e isso, quer no principio, quer na narração da causa, quer no final, tem tamanha força, se for tratado com delicadeza e julgamento, que muitas vezes tem mais poder do que a causa. Realiza-se tanto por determinado julgamento e método oratórios, que se forja, por assim dizer, o caráter do orador; por meio de determinado tipo de pensamentos e determinado tipo de palavras, empregando-se ainda uma atuação branda e que expresse afabilidade, consegue-se que pareçamos homens honestos, de boa indole, bons. ${ }^{41}$

Foram esses ensinamentos que fundamentaram Richer de Reims no seu projeto de construção do personagem de Gerberto, fazendo-se necessário todo o enaltecimento às transformações realizadas por aquele no comando dos estudos em Reims. Foi fundamental que Reims tivesse passado por toda a transformação curricular realizada por Gerberto, fazendo com que os monges pudessem ter acesso a essas obras.

Que tenha existido a aproximação a partir de uma relação aluno-professor entre Richer de Reims e Gerberto, não há provas documentais. Há, entretanto, uma discussão, onde Justin Lake afirma que não se pode afirmar esse intercâmbio direto, enquanto que Oscar Darlington, Uta
Lindgren e Hélène Gasc afirmam que, mesmo sem documentos, pode-se concluir pela confirmação dessa relação. ${ }^{42} \mathrm{O}$ que existe é a utilização dos mesmos autores citados por Richer em seu texto, e que era bibliografia das aulas dadas por Gerberto em Reims. ${ }^{43}$ Assim, como os estudos de Richer estiveram sempre relacionados às questões retóricas, fica evidente ao longo do texto a utilização de ideais clássicos na composição da narrativa histórica. Escrever a história, dessa forma, significa assumir uma relação muito próxima com a construção dos personagens com o intuito de referenciá-los como "honestos, de boa índole, bons", conforme apontava Cícero. Os estudos sobre a disciplina retórica estão apontados por Richer em uma parte fundamental da sua obra, o Livro III, entre os capítulos 46-54, em que, durante todos esses excertos, aparece uma longa e contemplativa exposição sobre as artes e os saberes, tendo como figura central Gerberto de Aurillac. ${ }^{44}$

Obviamente, a retórica não se constitui, em Richer, um aparato único, mas, sim, relacionado com a influência da oratória. Com uma concepção clássica, ainda pelas noções de Cícero, ${ }^{45}$ pode-se afirmar que apresenta uma preferência pela aparência da verdade (verisimile) sobre a rigorosa precisão factual (verum), com o objetivo de elucidar os motivos que levaram os agentes a determinada ação no passado. Cícero busca os fundamentos - e é isso que Richer faz em seu texto -, que são adquiridos a partir dos nomes, das datas e dos fatos, para, então, concatená-los em ideias conexas, em uma estrutura retórica (exaedificatio), onde o importante é a relação que surge entre a figura histórica, seus atos, e o resultados destes atos, que são os eventos. Tudo

\footnotetext{
40 CICERO, Marco Túlio. Retórica a Herênio. Tradução e introdução de Ana Paula Celestino Faria e Adriana Seabra. São Paulo: Hedra, 2005 ${ }_{41}$ CICERO, De or. II, 183-184: Horum igitur exprimere mores oratione iustos, integros, religiosos, timidos, perferentis iniuriarum mirum quiddam ualet; et hoc uel in principiis uel in re narranda uel in perorando tantam habet uim, si est suauiter et cum sensu tractatum, ut saepe plus quam causa ualeat. Tantum autem efficitur sensu quodam ac ratione dicendi, ut quasi mores oratoris effingat oratio; genere enim quodam sententiarum et genere uerborum, adhibita etiam actione leni facilitatemque significante efficitur, ut probi, ut bene morati, ut boni uiri esse uideamur. 42 LAKE, 2013, p. 187.

43 Virgilio, Estácio, Terêncio, Juvenal, Persius, Horácio e Lucano. Estes autores estão citados por Richer em HIST., III, 47. Quid provehendis rhethoricis providerit

Necnon et quatuor de topicis differentiis libros, de sillogismis cathegoricis duos, de ypotheticis tres, diffinitionumque librum unum, divisionum aeque unum utiliter legit et expressit. Post quórum laborem, cum ad rhethoricam suos provehere vellet, id sibi suspectum erat, quod sine locutionum modis, qui in poetis discendi sunt, ad oratoriam artem ante perveniri nom queat. Poetas igitur adhibuit quibus assuescendos arbitrabatur. Legit itaque ac docuit Maronem et Statium Terentiumque poetas, luvenalen quoque ac Persium Horatiumque satiricos, Lucanum etiam historiographum. Quibus assuefactos locutionumque modis compositos, ad rhethoricam transduxit.

44 RICHER, HIST. III, 47.

45 LAKE, 2013, p. 198.
} 
isso partindo de uma explicação sobre as causas e motivações. ${ }^{46}$ E a essência destes componentes, segundo Justin Lake, reside na composição dessa estrutura retórica a partir dos discursos ficcionais. ${ }^{47}$ As falas servem para a construção dessa estrutura a partir da oratória dos personagens que aparecem no relato. Os discursos oratórios aparecem com a função de embelezar ${ }^{48}$ e expor, dentro desse projeto estético/retórico, as explicações acerca das motivações dos personagens. Além, acredito, de construir uma narrativa dramática dentro do relato histórico. Um protagonismo deste historiador medieval também no sentido dessa nova forma de narrativa.

Justin Lake afirma que não há como saber quais foram as motivações que tiveram os historiadores medievais para a composição dos seus relatos orais, das falas dos personagens, entretanto, a utilização gera um aspecto interessante para a compreensão de uma forma de escrita histórica, que, portanto, aparece como dependente de um tradição retórica e oratória que remonta à Antiguidade. A retórica e a oratória são perfeitos exemplos dessa busca e reformulação. E isso também direciona para a imagem que deve ser destacada, a partir das ações, sobre o personagem que aparece no texto. Dominique Barthélemy, em seu livro A cavalaria, afirma sobre as Histórias que:

Richer toma emprestado a César elementos sobre a Gália que the permitem falar sobre o caráter duplo desses povos guerreiros: ao mesmo tempo ousados e briguentos, capazes de mortes e de fúria, mas também cheios de razão e eloquência. Todos unem sabedoria à audácia. ${ }^{49}$

Barthélemy parte da análise sobre o capítulo 3. do livro I, quando Richer de Reims descreve sobre os costumes dos habitantes da Gália. ${ }^{50}$ Portanto, temos assim os dignos de relato, que devem não apenas serem audazes em suas atividades - até mesmo nas violentas -, mas principalmente sábios em suas decisões.

O estudo da oratória/retórica em Richer é um dos pontos fundamentais sobre a leitura do seu texto, porque há a construção de discursos ao longo de todo o livro; além de fazer muitas citações a autores clássicos, o que permite com que saibamos a quais modelos anteriores ele se baseia para a composição do seu relato, os quais Lake fez um levantamento importante a partir de outros autores contemporâneos a Richer: Widukind de Corvey, com sua Res gestae Saxonicae (ca. 967973); Aimoin de Fleury, com Gesta Francorum (ca. 997-999); e Saint- Quentain, Gesta Narmannorum (ca. 996-1020). Sobre a composição retórica a partir de construção de falas dos personagens, nota-se claramente um predomínio da influência de Cícero sobre a invenção de discursos nas Histórias de Richer de Reims. ${ }^{51}$

Com esse método, o que fica exposto nas Histórias é um processo de criação do passado, ${ }^{52}$ que visa recuperar o que a memória não consegue guardar. Mas essa criação está totalmente relacionada com o desejo do autor em dar a sua opinião sobre o contexto político, 53 por isso que há um método de composição em que o objetivo do texto visa passar por cima de uma suposta "história coletiva, social", 54 demonstrando a superioridade do texto escrito, que seria utilizado para supostamente corrigir determinadas falhas. Por isso, acredito que a análise sobre a construção dos personagens deve se dar, principalmente, a partir do entendimento de que Richer constrói a imagem de alguns com o intuito de oficializar uma visão que se sobreporia às demais visões que estariam presentes na sociedade, circulando pela tradição e pela oralidade, baseadas unicamente

\footnotetext{
REYNOLDS, L. D. Texts and Transmission. A Survey of the Latin Classics. Oxford: Oxford University Press, 1983. p. 102-109.

LAKE, 2013, p. 198.

O termo foi utilizado por LAKE, 2013b, p. 198.

BARTHÉLEMY, Dominique. A Cavalaria. Da Germânia antiga à França do século XIl. Campinas, SP: Editora da Unicamp, 2010. p. 154

RICHER, HIST., I, 3. Ominium ergo Galliarum Populi innata audatia plurimum efferuntur, calumniarum impatientes. Si incitantur, cedibus exultant, efferatique inclementius adoriuntur. Semel persuasum ac rationibus approbatum vix refellere consuerunt. Unde et Hieronimus 'Sola', inquit, 'Gallia monstra non habuit, sed viris prudentibus et eloquentissimis semper claruit'.

51 LAKE, 2013, p. 199.

52 GEARY, Patrick J. Phantoms of Remembrance. Memory and Oblivion at the End os the First Millenium. Princeton, New Jersey: Princeton University Press, 1994. p. 7.

53 Ibidem.

54 Ibidem, p. 12
} 
na rememoração. A história escrita é, assim, para Richer - e acredito que para os outros historiadores medievais também - superior a qualquer outro tipo de intuito memorialista; e com um ideal estético que compõe todo o instrumental de Richer de Reims, especificamente.

\section{Considerações finais}

Quando Bernard Guenée afirma que "é preciso saber entender o silêncio dos historiadores",55 refere-se àquilo que não está presente no texto de maneira explícita, mas penso que também é necessário compreender o silêncio, no caso de Richer de Reims, como aquilo que ele optou por colocar em sua obra, na sua narrativa histórica, e o que ele resolveu deixar de fora. A seleção dos eventos por parte do historiador medieval me leva a refletir sobre outro tipo de silêncio, mais sutil, que é aquele em que o historiador pretendeu indicar, mas, por certo pudor metodológico, talvez, não pôde explicitar nas orações. Acredito que quando ele adjetiva com as melhores qualidades alguns dos personagens, os silêncios se dissipam, e aquele referenciado se torna, assim, um personagem ideal. Toda essa construção se dá a partir da construção retórica no texto de Richer de Reims, que escreveu, portanto, para enaltecer alguns e desmerecer outros. E a utilização de diálogos aparece como um intrumento estético para esse intuito retórico richeriano. Portanto, parto do pressuposto acumulativo de que:

a) Richer de Reims é um historiador consciente de sua ação enquanto tal, porque seleciona informações para compor a sua obra;

b) possui um conhecimento sobre saberes que lhe permitiu que pudesse ser protagonista na composição de sua narrativa, principalmente a partir de seus estudos dentro de um espaço específico, que foi Reims;

c) construiu a imagem de seus personagens a partir deste aparato estético/ retórico, que, ao narrar sobre os feitos, sobre as virtudes, direcionava a compreensão de um lado específico da história. Para tal, a análise dos diálogos dos personagens se faz fundamental na compreensão da escrita richeriana.

Em resumo, o intento é demonstrar como a partir de uma concepção clássica de escrita, somada a um contexto histórico especifico, se deu a construção de alguns personagens na obra de História de Richer de Reims. O historiador reconstruiu a história, reescrevendo-a, de maneira intencional, querendo apontar a uma construção enquanto aparato estético/retórico no texto. Foi essa "reescrita da história" que fez com que sua obra ficasse conhecida pela historiografia contemporânea, ${ }^{56}$ e nos permita lê-la hoje ainda na sua multiplicidade interpretativa.

\section{Referências}

BARTHÉLEMY, Dominique. A Cavalaria: da Germânia antiga à França do século XII. Campinas: Editora da Unicamp, 2010.

BOUCHARD, Constance B. Feudalism, Cluny, and the Investiture Controversy. In: BLANKS, David; FRASSETTO, Michael; LIVINGSTONE, Amy. Medieval monks and their world: ideas and realities. Leiden/Boston: Brill, 2006. https://doi.org/10.1163/9789047411369_007

CiCERO, Marco Túlio. Retórica a Herênio. Tradução e introdução de Ana Paula Celestino Faria e Adriana Seabra. São Paulo: Hedra, 2005

GEARY, Patrick J. Phantoms of Remembrance. Memory and Oblivion at the End os the First Millenium. Princeton, New Jersey: Princeton University Press, 1994.

GINZBURG, Carlo. Sinais. Raizes de um paradigma indiciário. In: GINZBURG, Carlo. Mitos, Emblemas, Sinais. São Paulo: Companhia das Letras, 1989. p. 143-179.

GLENN, Jason. Politics and History in the Tenth Century: The work and world of Richer of Reims. Cambridge: Cambridge University Press, 2004.

GUADET, Joseph (tr.). Histoire de son temps. Paris, Societé de l'histoire de France, 1845. 2 v.

GUENÉE, Bernard. Histoire et culture historique dans l'Occident médiéval. Paris: Aubier, 1980.

LAKE, Justin (ed./tr.). Richer of Saint-Rémi. Histories. Dumbarton Oaks Medieval Library, Harvard University Press, 2011. 2 V.

\footnotetext{
55 GUENÉE, Bernard. Histoire et culture historique dans l'Occident médiéval. Paris: Aubier, 1980. p. 529

56 LAKE, 2013, p. 185.
} 
LAKE, Justin. Gerbert of Aurillac and the Study of Rhetoric in Tenth-Century Rheims. The Journal of Medieval Latin, Toronto, v. 23, p. 49-85, 2013. https://doi. org/10.1484/J.JML.1.103772

LAKE, Justin. Richer of Saint-Rémi. The Methods and Mentality of a Tenth-Century Historian. Washington: Catholic University of America Press, 2013.

LE GOFF, J. Os Intelectuais na Idade Média. Rio de Janeiro: José Olympio, 2003.

POINSIGNON, Auguste Maurice (tr.). Richeri historiarum quatuor libri. Reims: Pub. de l'Academie de Rheims, 1855.

REYNOLDS, L. D. Texts and Transmission. A Survey of the Latin Classics. Oxford: Oxford University Press, 1983.

SAINT-REMI, Richer di. I quattro libri delle Storie (888998). Pisa: Edizioni Plus - Pisa University Press, 2008.

SILVEIRA, Verônica da Costa. Identidades Politicas e Políticas Identitárias na Gália Merovingia e Hispânia Visigoda. 2015. Tese (Doutorado em História) -- Programa de Pós-Graduação em História Social, Faculdade de Filosofia, Letras e Ciências Humanas, Universidade de São Paulo, São Paulo, 2015. p. 252.

TEIXEIRA, I. S. O Intelectual na Idade Média: divergências historiográficas e proposta de análise. Revista Diálogos Mediterrânicos, Curitiba, v. 7. p. 155-173, 2014.

VERGER, Jacques. Homens de saber na Idade Média. Bauru, SP: EDUSC, 1999.

\section{Endereço para correspondência}

Rafael Bassi

Pontificia Universidade Católica do Rio Grande do Sul

Av. Ipiranga, 6681, Prédio $8,4^{\circ}$ andar

Partenon, 90619900

Porto Alegre, RS, Brasil 